\title{
Optimization of SHEPWM cascaded multilevel inverter switching patterns
}

\author{
Ayong Hiendro, Ismail Yusuf, Junaidi, F. Trias Pontia Wigyarianto, Yohannes M. Simanjuntak \\ Department of Electrical Engineering, Tanjungpura University, Indonesia
}

\begin{tabular}{l} 
Article Info \\
\hline Article history: \\
Received Jan 27, 2020 \\
Revised Apr 3, 2020 \\
Accepted Apr 24, 2020 \\
\hline
\end{tabular}

\section{Keywords:}

Cascaded H-bridge

Harmonic elimination

Multilevel inverter

Optimization technique

Switching angle

\begin{abstract}
Selective harmonic elimination (SHE) is an efficient method to eliminate low-order selected harmonics. However, due to nonlinearity in the problems, many optimization techniques give unsatisfied performances in finding optimum switching angles for the SHE. This paper proposes a modified moth-flame optimization algorithm to eliminate selective harmonics in cascaded multilevel inverters. The optimization algorithm is employed to find sets of optimum switching angles for cascaded 5-level, 7-level, and 9level inverters. The results have shown that modified moth-flame optimization is beneficial in finding optimum switching angles. It performs better than moth-flame optimization (MFO) and differential evolution (DE) algorithms. The optimum switching angles are applied to generate switching pulses for a cascaded 9-level inverter to demonstrate the algorithm's accuracy. As a result, the low-order harmonics are entirely removed from the ac output voltage of the inverter.
\end{abstract}

This is an open access article under the CC BY-SA license.

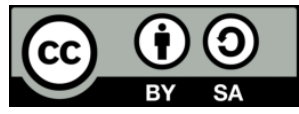

\section{Corresponding Author:}

Ayong Hiendro,

Department of Electrical Engineering,

Tanjungpura University,

Jl. Jenderal Ahmad Yani, PontianakKalimantan Barat, Indonesia.

Email: ayong.hiendro@ee.untan.ac.id

\section{INTRODUCTION}

Multilevel inverters have attracted the attention of many researchers due to the need for high power applications in industries [1]. In high power applications, the switching frequency of inverters is limited by switching losses and electromagnetic interferences. As the switching frequency and switching losses are decreased, the efficiency of inverters is increased significantly [2].

The advantages of the multilevel inverters are a) they can produce almost sinusoidal waveform output voltage with very low total harmonic distortion (THD), b) they can operate at low switching frequency [3], and c) they are applicable for high power and high voltage systems. There are commonly three types of multilevel inverter topologies: flying capacitor [4], diode-clamp [5, 6], and cascaded multilevel inverter [7]. Among the topologies, the cascaded multilevel inverter becomes more attractive for medium and high voltage renewable energy systems due to its modularity and simplicity [8]. Another advantage of the cascaded multilevel inverter is that it requires less number of components than diode-clamp and flying capacitor inverters.

One of the crucial issues in multilevel inverters is to eliminate harmonics of the ac output voltage. Selective harmonic elimination pulse width modulation (SHEPWM) [9-12] is the most popular technique to improve the output voltage waveform of multilevel inverters. The SHEPWM technique can be utilized to reduce both the switching frequency and THD value of the multilevel inverters. Therefore, it would give a significant advantage for high-power multilevel inverters to operate with low switching frequencies [13]. 
However, accurate estimating of switching patterns plays a crucial role in SHEPWM inverters. The main problem associated with the SHEPWM technique is the solution of nonlinear equations under various operating conditions of the inverters $[14,15]$.

There are two main methods for solving a set of SHEPWM transcendental equations: deterministic [16] and stochastic [17, 18] approaches. Optimization techniques, especially stochastic metaheuristic algorithms [19], have become the exciting tools to deal with complex optimization problems in SHEPWM inverters. However, due to nonlinearity and multiple variables existed in the issues, many optimization algorithms give unsatisfied performances for their premature or slow convergence.

In this paper, a modified MFO is employed to find sets of optimum switching angles for SHEPWM cascaded 5-level, 7-level, and 9-level inverters. The optimization problem for the cascaded multilevel inverters is computed by using Matlab. The pulses generated from optimum switching patterns and power circuits are built by using Cadence-Pspice. Finally, results are obtained and verified in simulations for a cascaded 9-level inverter.

\section{CASCADED MULTILEVEL INVERTER}

A cascaded multilevel inverter consists of $N$ single-phase H-bridge inverters with separate $N$ dc sources. The single-phase H-bridge inverters are connected in series, as shown in Figure 1. It also shows that the cascaded multilevel inverter has equal dc sources,

$$
V_{d c 1}=V_{d c 2}=\cdots V_{d c N}=V_{d c}
$$

Each single-phase H-bridge inverter requires one dc source, or in other words, the cascaded (2N+1)level inverter requires $N$ dc sources [20,21]. However, the cascaded multilevel inverter can also be supplied by a single DC source $[22,23]$. The multilevel inverter could produce medium- to high-voltage output from low-voltage input. The ac output voltage is synthesized by $N$ dc voltage sources connected to the individual H-bridge inverters.

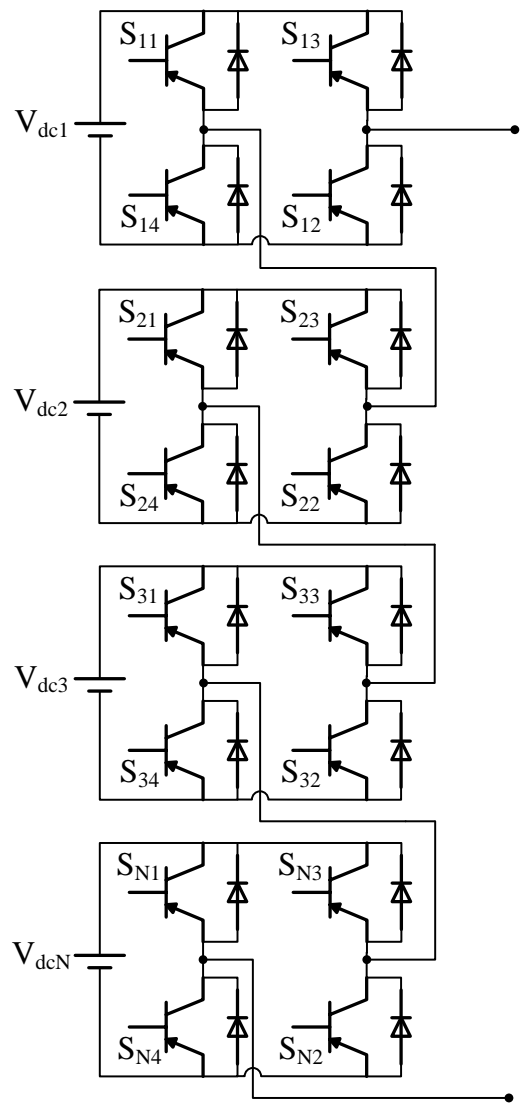

Figure 1. The power circuit of cascaded (2N+1)-level inverter 
The summation of voltages generated by each H-bridge inverter produces a staircase output voltage waveform (as seen in Figure 2). Each single-phase $\mathrm{H}$-bridge inverter generates $+V_{d c}, 0$, and $-V_{d c}$ output, and the resulting output voltage of a cascaded $(2 N+1)$-level inverter ranges from $-N V_{d c}$ to $N V_{d c}$.

Figure 2 presents the output voltage waveform of the cascaded $(2 N+1)$-level inverter, which can be expressed in Fourier series as follows:

$$
v(\omega t)=\sum_{n=1,3,5, \ldots}^{N} V_{n} \sin (n \omega t)
$$

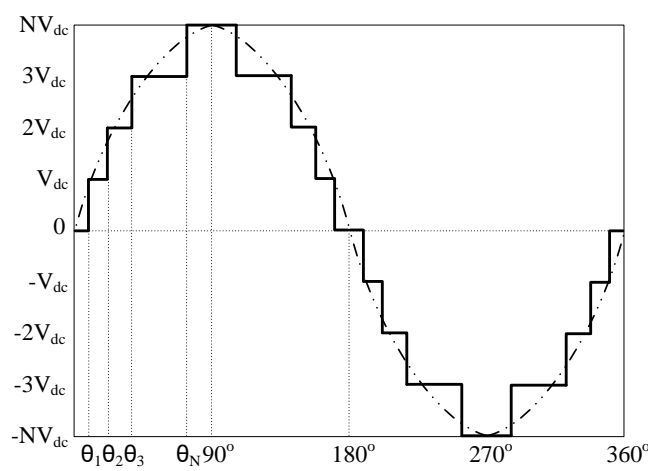

Figure 2. The output voltage waveform of a cascaded $(2 N+1)$-level inverter

The magnitude of harmonic components (including the fundamental) for equal dc sources is given by

$$
V_{n}=\frac{4 V_{d c}}{n \pi}\left[\sum_{k=1}^{N} V_{n} \cos \left(n \theta_{k}\right)\right]
$$

The main goal of the SHEPWM is to eliminate $(N-1)$ harmonics from the waveform. The remaining equation is used as the magnitude of the fundamental component at the desired value, $V_{l}$. Based on (3), the simultaneous equations for determining $N$ switching angles of the SHEPWM is given by

$$
\begin{aligned}
& f_{1}(\theta)=\frac{4}{\pi M}\left[\sum_{k=1}^{N} \cos \left(\theta_{k}\right)\right]-1=\varepsilon_{1} \\
& f_{3}(\theta)=\frac{V_{3}}{V_{1}}=\frac{4}{3 \pi M}\left[\sum_{k=1}^{N} \cos \left(3 \theta_{k}\right)\right]=\varepsilon_{3} \\
& f_{5}(\theta)=\frac{V_{5}}{V_{1}}=\frac{4}{5 \pi M}\left[\sum_{k=1}^{N} \cos \left(5 \theta_{k}\right)\right]=\varepsilon_{5} \\
& f_{(2 N-1)}(\theta)=\frac{V_{(2 N-1)}}{V_{1}}=\frac{4}{5 \pi M}\left[\sum_{k=1}^{N} \cos \left((2 N-1) \theta_{k}\right)\right]=\varepsilon_{(2 N-1)}
\end{aligned}
$$

where $f_{3}, f_{5}, \ldots, f_{(2 N-1)}$ is the normalized magnitude of harmonics (respect to the fundamental), and $M=V_{l} / V_{d c}$ is the modulation index. The objective function of the SHEPWM problem is defined as

$$
\varepsilon=\left|\varepsilon_{1}\right|+\left|\varepsilon_{3}\right|+\left|\varepsilon_{5}\right|+\cdots+\left|\varepsilon_{(2 N-1)}\right|
$$

The optimum switching angles are obtained by minimizing (5) and must satisfy the following constraint:

$$
0^{o}<\theta_{1}<\theta_{2}<\cdots<\theta_{(2 N-1)}<90^{\circ}
$$

The first of (4) guarantees the desired fundamental component, and the others are utilized to ensure the elimination of $3^{\text {rd }}, 5^{\text {th }}, 7^{\text {th }}, 9^{\text {th }}, \ldots$, and $(2 N-1)^{\text {th }}$ harmonics. 


\section{MODIFIED MOTH-FLAME OPTIMIZATION ALGORITHM}

The moth flame optimization (MFO) algorithm uses moths as search agents that move around the search space [24]. Flames are considered as the best position of moths in the search space. Each moth searches around a flame and updates the discovery as its best solution.

In solving the SHE problems, the optimum switching angles are the best position of moths in the MFO algorithm. The initial parameters of the MFO are the moth population $N$, the number of variables $D$, the lower bound $l_{b}$, the upper bound $u_{b}$, and the maximum iteration Max. The lower and upper bounds of variables are defined as follows

$$
l b_{j}=\left[\begin{array}{llll}
l b_{1} & l b_{2} & \ldots & l b_{D}
\end{array}\right], u b_{j}=\left[\begin{array}{llll}
u b_{1} & u b_{2} & \ldots & u b_{D}
\end{array}\right]
$$

The moth population is randomly generated by

$$
M_{i, j}^{(I=1)}=l b_{j}+\operatorname{rand}_{j} .\left(u b_{j}-l b_{j}\right), i=1,2, \ldots, N ; j=1,2, \ldots, D
$$

The moth population of the MFO can be presented as

$$
M_{i, j}{ }^{(I)}=\left[\begin{array}{cccc}
M_{1,1} & M_{1,2} & \cdots & M_{1, D} \\
M_{2,1} & M_{2,2} & \cdots & M_{2, D} \\
M_{3,1} & M_{3,2} & \cdots & M_{3, D} \\
\vdots & \vdots & \ddots & \vdots \\
M_{N, 1} & M_{N, 2} & \cdots & M_{N, D}
\end{array}\right]
$$

The fitness value of the moths is carried out by using

$$
M F_{i}^{(I=1)}=f\left(M_{i, j}^{(I=1)}\right), i=1,2, \ldots, N ; j=1,2, \ldots, D
$$

The fitness value can be presented as

$$
M F_{i}^{(I)}=\left[\begin{array}{c}
M F_{1} \\
M F_{2} \\
M F_{3} \\
\vdots \\
M F_{N}
\end{array}\right]
$$

During the iteration process, the flame fitness (at $I=1$ ) is sorted of initial fitness values of the moths, whereas the flames are sorted according to their fitness values. The flame fitness is sorted from the best to the worst values,

$$
\begin{aligned}
& F F_{i}^{(I)}=\operatorname{sorted}\left(M F_{i}^{(I)}\right)=\left[\begin{array}{c}
F F_{1} \\
F F_{2} \\
F F_{3} \\
\vdots \\
F F_{N}
\end{array}\right]^{(I)} \\
& F_{i, j}{ }^{(I)}=\left[\begin{array}{cccc}
F_{1,1} & F_{1,2} & \cdots & F_{1, D} \\
F_{2,1} & F_{2,2} & \cdots & F_{2, D} \\
F_{3,1} & F_{3,2} & \cdots & F_{3, D} \\
\vdots & \vdots & \ddots & \vdots \\
F_{N, 1} & F_{N, 2} & \cdots & F_{N, D}
\end{array}\right]^{(I)}
\end{aligned}
$$

Updating the moth population is using a logarithmic spiral model as follows

$$
M_{i, j}{ }^{(I+1)}=S_{i, j}{ }^{(I)} \cdot e^{(b t)} \cdot \cos (2 \pi t)+F_{i, j}{ }^{(I)}
$$

where $S$ is the distance between the moths and the flames, $b$ is a shape constant of the spiral path $(-1 \leq b \leq 1)$, $t$ is a control parameter to maintain the distance between moth and flame in the spiral path $(r \leq t \leq 1)$, and $r$ is a convergence constant which is decreasing from -1 to -2 to estimate the values of $t$. 
The distance between the moths and the flames is defined as

$$
S_{i, j}{ }^{(I)}=\operatorname{abs}\left(F_{i, j}{ }^{(I)}-M_{i, j}^{(I)}\right), i=1,2, \ldots, N ; j=1,2, \ldots, D
$$

whereas $r$ and $t$ are as follows

$$
r=-\left(1+\frac{I}{\operatorname{Max}}\right), t=\operatorname{rand} .(r-1)+1
$$

The position of updating moths could eventually degrade after passing iterations. In order to ensure that the moths will meet the flames, the moths should update their positions with respect to the best flames at the final step of the iteration. A control parameter necessary for this mechanism is

$$
F N=\operatorname{round}\left(N-\frac{(N-1) \cdot I}{\operatorname{Max}}\right)
$$

According to (17), the moth population is updated by using

$$
\begin{aligned}
& M_{i, j}{ }^{(I+1)}=S_{i, j}{ }^{(I)} \cdot e^{(b t)} \cdot \cos (2 \pi t)+F_{i, j}{ }^{(I)}, \text { if } I \leq F N \\
& M_{i, j}{ }^{(I+1)}=S_{i, j}{ }^{(I)} \cdot e^{(b t)} \cdot \cos (2 \pi t)+F_{F N, j}{ }^{(I)}, \text { if } I>F N
\end{aligned}
$$

while updating the flames:

$$
F F_{i}^{(I+1)}=\operatorname{sorted}\left[\begin{array}{c}
M F_{i}^{(I+1)} \\
F F_{i}^{(I)}
\end{array}\right], i=1,2, \ldots, N
$$

The flame corresponding to its fitness value is

$$
F_{i, j}{ }^{(I+1)}=\left[\begin{array}{cccc}
F_{1,1} & F_{1,2} & \cdots & F_{1, D} \\
F_{2,1} & F_{2,2} & \cdots & F_{2, D} \\
F_{3,1} & F_{3,2} & \cdots & F_{3, D} \\
\vdots & \vdots & \ddots & \vdots \\
F_{N, 1} & F_{N, 2} & \cdots & F_{N, D}
\end{array}\right]^{(I+1)}
$$

Finally, the best position of the moths and their fitness values are selected in here as

$$
\begin{aligned}
& F F_{\text {best }}{ }^{(I+1)}=F F_{1}{ }^{(I+1)} \\
& F_{\text {best }}{ }^{(I+1)}=F_{1, j}{ }^{(I+1)},, j=1,2, \ldots, D
\end{aligned}
$$

Updating the moths and the flames processes are repeated until FFbest(I+1) meets the criterion $\varepsilon$ as defined in (5) and/or I = Max.

\section{RESULTS AND ANALYSIS}

\subsection{Switching patterns}

Achieving the fundamental component at a desired of $M$ and suppressing selected harmonics to zero as describing in (4) are very difficult to be solved numerically. In this work, a modified MFO algorithm is applied to alleviate the computational problems. The optimum switching angles for cascaded 5-level, 7-level, and 9-level inverter are explored by using the modified MFO for all values of $M$. As the results, the optimum switching angles for the cascaded 5-level, 7-level, and 9-level inverter are presented in Figure 3, 4, and 5, respectively. All optimum switching angles must meet the requirements of (6), as mentioned earlier. Thus, there are no possible optimum switching angles within $M<1.1027$ for a cascaded 5-level inverter. Using the same constraint which must satisfy (6), there are also no optimum switching angles within $M<2.0974$ for a cascaded 7-level inverter and within $M<3.0930$ for a cascaded 9-level inverter. It is noted that not all $M$ has its solutions for the optimum switching angles since the optimum switching angles will only be applicable if they fulfill the requirement as defined by (6). 


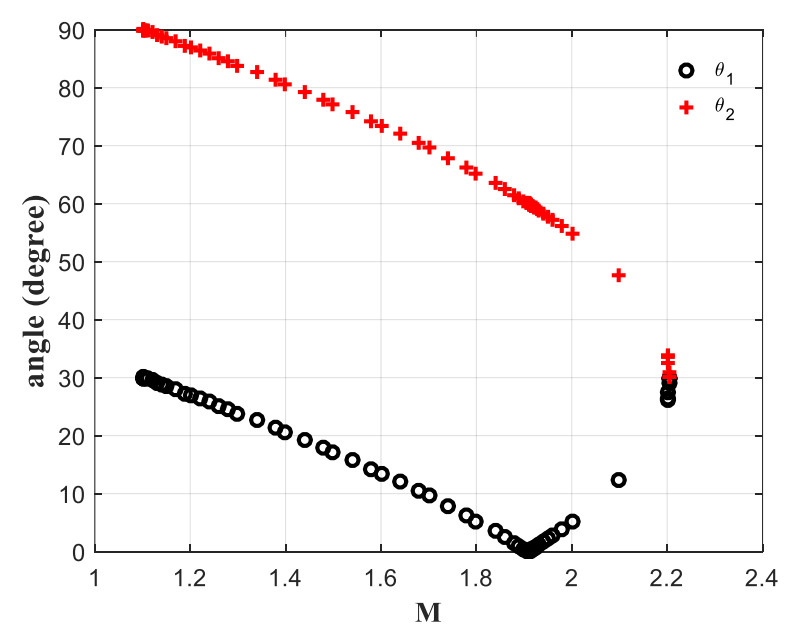

Figure 3. Optimum switching patterns for cascaded 5-level inverter

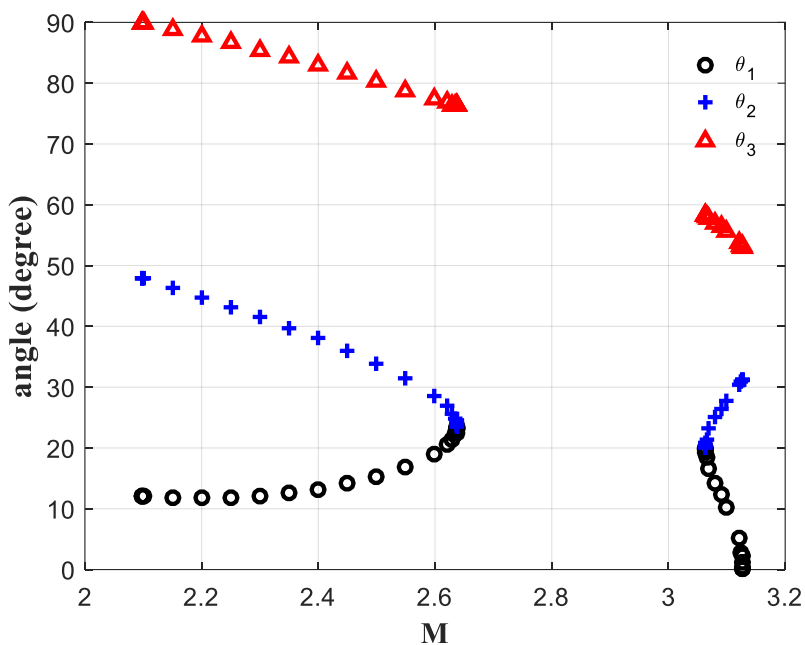

Figure 4. Optimum switching patterns for cascaded 7-level inverter

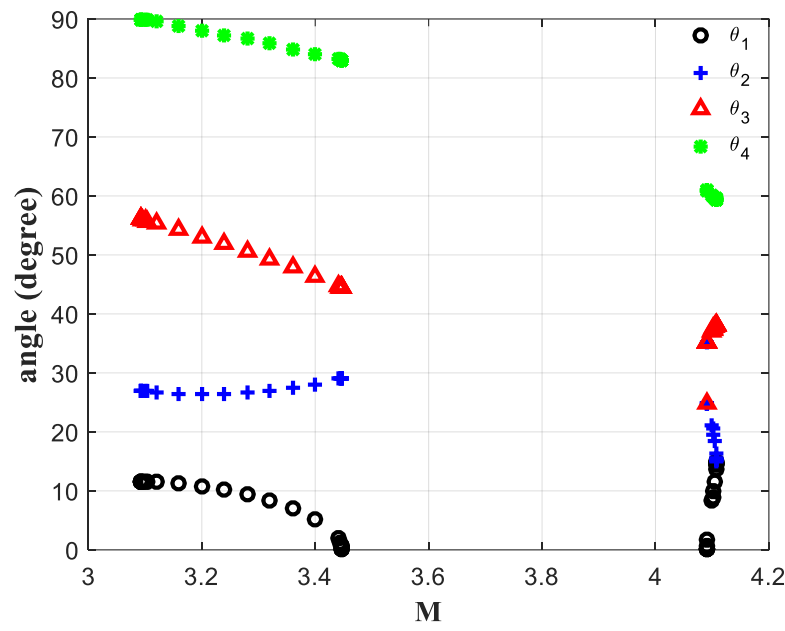

Figure 5. Optimum switching patterns for cascaded 9-level inverter 


\subsection{Modified MFO performance}

The modified MFO algorithm is compared to MFO and DE algorithms in order to verify its performance. These algorithms are analyzed by using the same objective function, as mentioned in (4-6). The approach using is to stop iterations when the searching processes have reached $\varepsilon<10^{-7}$. Twenty independent experiments are carried out for each algorithm. As the results, the average number of iterations required by the modified MFO is 115 iterations, while the MFO and the DE need 131 and 182 iterations, respectively. Comparison to both MFO and DE algorithms, it is revealed that the modified MFO gives better performance in finding optimum switching angles (as seen in Figure 6). The modified MFO is convergence faster than MFO and DE algorithms.

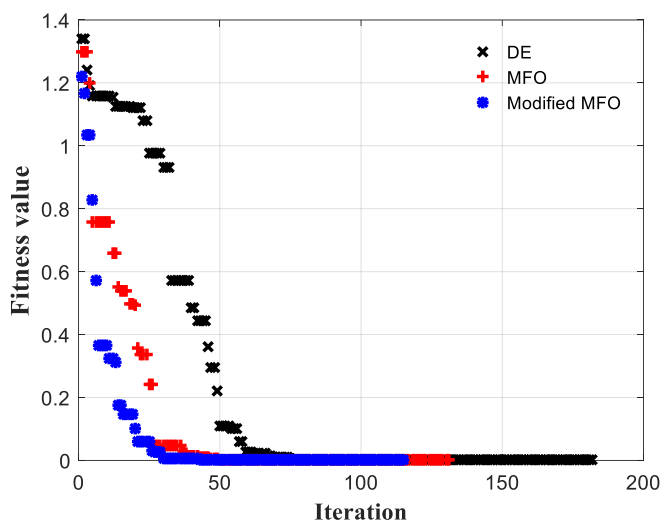

Figure 6. Fitness value curves for $\varepsilon<10^{-7}$

\subsection{Cascade 9-level inverter}

In order to generate output ac voltage from a cascaded multilevel inverter, the parameters used in simulations are: cascaded 9-level, $V_{d c}=100 \mathrm{~V}, M=3.2$, and $f=50 \mathrm{~Hz}(T=20 \mathrm{~ms})$. The set of optimum switching angles found for $M=3.2$ are: $\theta_{1}=10.8169^{\circ}, \theta_{2}=26.3546^{\circ}, \theta_{3}=53.0106^{\circ}$, and $\theta_{4}=88.0910^{\circ}$. The time delay and pulse width during the PWM control of the inverter are derived from the optimum switching angles. The switching patterns are presented in Figures 7 and 8.

The simulation results at a modulation index $M=3.2$ are given in Figure 9. From the frequency spectra, it can be seen that the magnitudes of low-order harmonics such as the $3^{\text {rd }}, 5^{\text {th }}$, and $7^{\text {th }}$ have been omitted from the waveform entirely.

The residual higher-order harmonics are: $\mathrm{V}_{9} / \mathrm{V}_{1}=3.6665 \%, \mathrm{~V}_{11} / \mathrm{V}_{1}=4.4569 \%, V_{13} / V_{1}=4.4684 \%$, $V_{15} / V_{1}=0.9545 \%, V_{17} / V_{1}=3.3251 \%, V_{19} / V_{1}=4.0786 \%, V_{21} / V_{1}=0.3430 \%$. The measured value of $V_{1}$ is $319.843 \mathrm{~V}$. It matches with the calculated $V_{1}$ for $M=0.8$, which is $V_{1}=310 \mathrm{~V}$. Each higher-order harmonic component is lesser than 5\% with total harmonic distortion (THD) of $9.95 \%$. The THD of output voltage can be reduced by applying an LC passive filter to minimize the high-order harmonics [25].

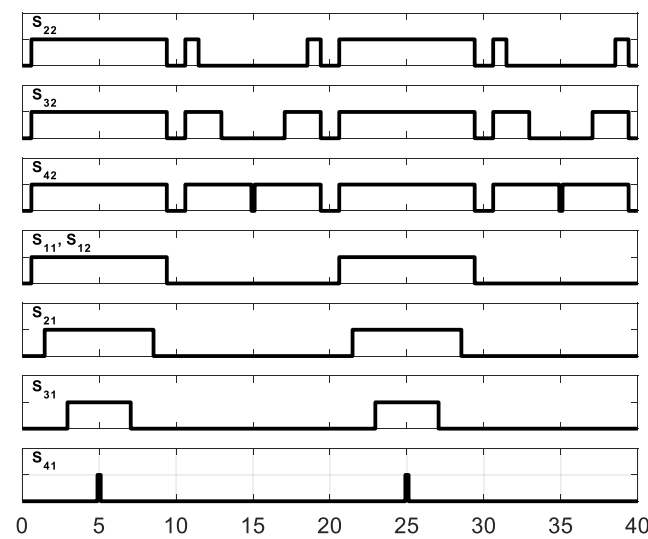


Figure 7. Switching pulses for a cascaded 9-level inverter: $S_{11}, S_{12}, S_{21}, S_{22}, S_{31}, S_{32}, S_{41}, S_{42}$
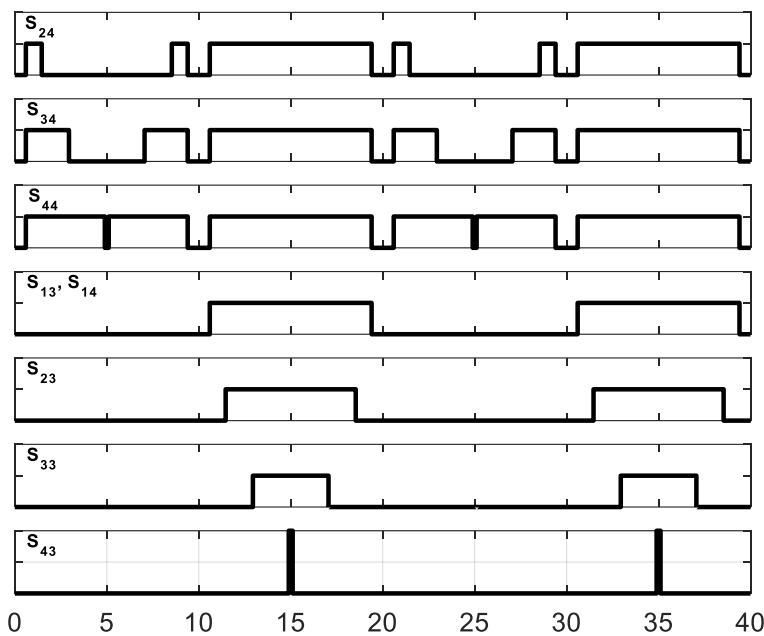

Figure 8. Switching pulses for a cascaded 9-level inverter: $\mathrm{S}_{13}, \mathrm{~S}_{14}, \mathrm{~S}_{23}, \mathrm{~S}_{24}, \mathrm{~S}_{33}, \mathrm{~S}_{34}, \mathrm{~S}_{43}, \mathrm{~S}_{44}$
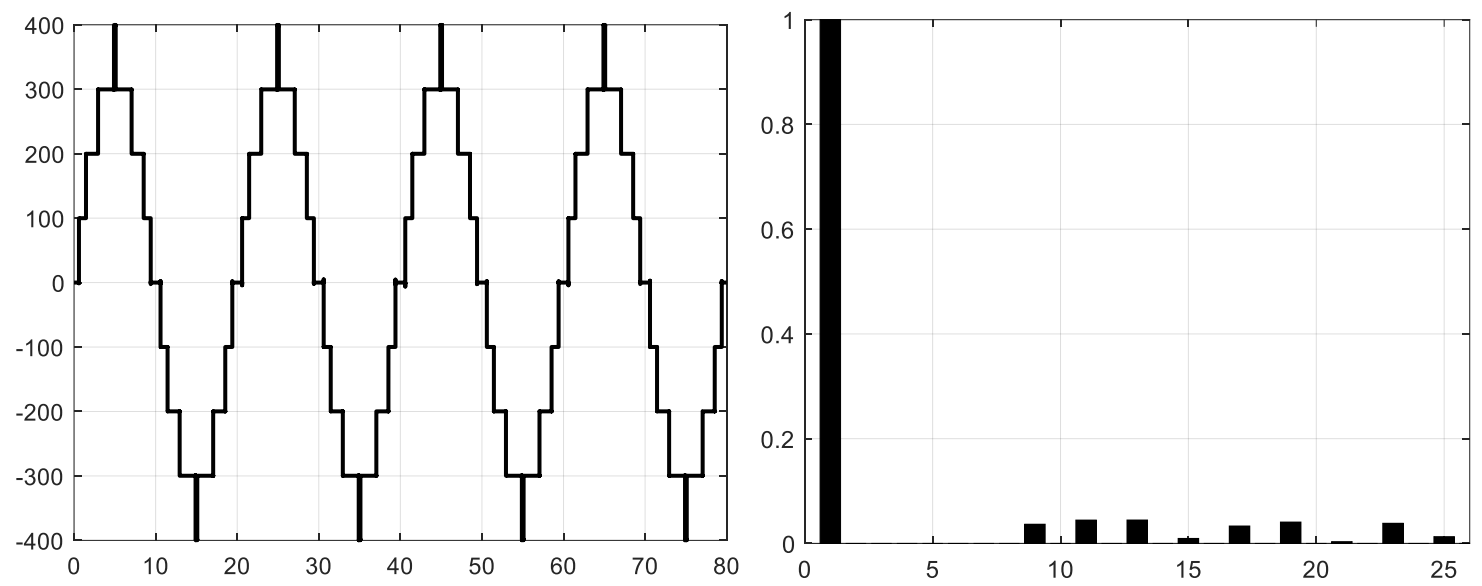

Figure 9. The output voltage waveform and the corresponding FFT analysis

\section{CONCLUSION}

A modified MFO algorithm has been proposed in order to overcome computational difficulties of SHEPWM cascaded multilevel inverters. The modified MFO algorithm provides precise computation of optimum switching angles for cascaded multilevel inverters. It is faster convergence than both MFO and DE algorithms. Simulation results are presented for a cascaded 9-level inverter in single-phase configuration. The results also show that the low-order harmonics are utterly eliminated from the ac output voltage waveform. It reveals that the modified MFO is an effective algorithm to solve SHE problems of cascaded multilevel inverters.

\section{REFERENCES}

[1] R.S. Alishah, S.H. Hosseini, "A New Multilevel Inverter Structure For High-Power Applications Using Multicarrier PWM Switching Strategy," International Journal of Power Electronics and Drive System (IJPEDS), vol. 6, no. 2, pp.318-325, 2015.

[2] E. Isen, A.F. Bakan, "Highly Efficient Three-Phase Grid-Connected Parallel Inverter System," Journal of Modern Power System and Clean Energy, vol. 6, no. 5, pp.1079-1089, 2018.

[3] M. Ahmed, E. Hendawi, M. K. Metwaly, "Single Phase Asymmetrical Cascaded MLI with Extreme Output Voltage Levels to Switch Ratio," International Journal of Power Electronics and Drive Systems (IJPEDS), vol. 9, no. 2, pp.712-721, 2018. 
[4] A. Khoshkbar-Sadigh, V. Dargahi, M. Abarzadeh, S. Darhgahi, "Reduce DC Voltage Source Flying Capacitor Multicell Multilevel Inverter: Analysis and Implementation," IET Power Electronics, vol. 7, no. 2, pp.439-450, 2014.

[5] N. Susheel, P.S. Kumar, "Performance Analysis of FPGA based Diode Clamped Multilevel Inverter Fed Induction Motor Drive using Phase Opposition Disposition Multicarrier Based Modulation Strategy," International Journal of Power Electronics and Drive System (IJPEDS), vol. 8, no. 4, pp.1512-1523, 2017.

[6] R. Castillo, B. Diong, P. Biggers, "Single-Phase Hybrid Cascaded H-Bridge and Diode-Clamp Multilevel Inverter with Capacitor Voltage Balancing," IET Power Electronics, vol. 11, no. 4, pp. 700-707, 2018.

[7] M. Malinowski, K. Gopakumar, J. Rodriguez, M.A. Pérez, "A Survey on Cascaded Multilevel Inverters, IEEE Transactions on Industrial Electronics, vol. 57, no. 7, pp. 2197-2206, 2010.

[8] A. Nami, F. Zare, A. Ghosh, F. Blaabjerg, "A Hybrid Cascade Converter Topology with Series Connected Symmetrical and Asymmetrical Diode Clamped H-Bridge Cells," IEEE Transactions on Power Electronics, vol. 26, no. 1, pp. 51-65, 2011.

[9] W. Fei, X. Ruan, B. Wu, "A Generalized Formulation of Quarter-Wave Symmetry SHE-PWM Problems for Multilevel Inverters," IEEE Transactions on Power Electronics, vol. 24(7), pp. 1758-1766, 2009.

[10] W. Fei, X. Du, B. Wu, "A Generalized Half-Wave Symmetry SHE-PWM Formulation for Multilevel Voltage Inverters," IEEE Transactions on Industrial Electronics, vol. 57(9), pp. 3030-3038, 2010.

[11] T.R. Sumithira, A.N. Kumar,"Elimination of Harmonics in Multilevel Inverters Connected to Solar Photovoltaic Systems Using ANFIS: An Experimental Case Study," Journal of Applied Research and Technology, vol.11(1), pp.124-132, 2013.

[12] L. K. Haw, M.S.A. Dahidah, H.A.F. Almurib, "SHE-PWM Cascaded Multilevel Inverter With Adjustable DC Voltage Levels Control for STATCOM Applications," IEEE Transactions on Power Electronics, vol. 29, no. 12, pp. 6433-6444, 2014.

[13] M.S.A. Dahidah, G. Konstantinou, V.G. Agelidis, "A Review of Multilevel Selective Harmonic Elimination PWM: Formulations, Solving Algorithms, Implementation, and Applications," IEEE Transactions on Power Electronics, vol. 30, no. 8, pp. 4091-4106, 2015.

[14] H. Behbahanifard, S. Abazari, A. Sadoughi, "New Scheme of SHE-PWM Technique for Cascade Multilevel Inverters with Regulation of DC Voltage Sources," ISA Transaction, vol. 97, pp. 44-52, 2020.

[15] S. Ahmad, M. Meraj, A. Iqbal, I. Ashraf, "Selective Harmonics Elimination in Multilevel Inverter by a DerivativeFree Iterative Method under Varying Voltage Condition," ISA Transaction, vol. 92, pp. 241-256, 2019.

[16] W.A. Halim, N.A. Rahim, M. Azri, "Selective Harmonic Elimination for a Single-Phase 13-Level TCHB Based Cascaded Multilevel Inverter Using FPGA,” Journal of Power Electronics, vol. 14, no. 3, pp. 488-498, 2014.

[17] R. Taleb, M. Helaimi, D. Benyoucef, Z. Boudjema, "Genetic Algorithm Application in Asymmetrical 9-level Inverter," International Journal of Power Electronics and Drive Systems (IJPEDS), vol. 7, no. 2, pp.521-530, 2016.

[18] M. Etesami, N. Ghasemi, D.M. Vilathgamuwa, W.L. Malan, "Particle Swarm Optimisation-Based Modified SHE Method for Cascaded H-bridge Multilevel Inverter," IET Power Electronics, vol. 10, no. 1, pp.18-28, 2017.

[19] M.A. Memon, S. Mekhilef, M. Mubin, M. Aamir, "Selective Harmonic Elimination in Inverters Using Bio-inspired Intelligent Algorithms for Renewable Energy Conversion Applications: A Review," Renewable and Sustainable Energy Reviews, vol. 82, pp.2235-2253, 2018.

[20] M.F. Kangarlu, E. Babaei, “A Generalized Cascaded Multilevel Inverter Using Series Connection of Submultilevel Inverters," IEEE Transactions of Power Electronics, vol. 28, no. 2, pp. 625-636, 2013.

[21] M.D. Siddique, S. Mekhilef, N.M. Shah, A. Sarwar, M. A. Memon, "A New Single-Phase Cascaded Multilevel Inverter Topology with Reduced Number of Switches and Voltage Stress," International Transactions on Electrical Energy Systems, vol. 30, no. 2, 2019.

[22] A. K. Panda, Y. Suresh, "Research on Cascade Multilevel Inverter with Single DC Source by Using Three-Phase Transformers," International Journal of Electrical Power \& Energy Systems, vol. 40, no. 1, pp. 9-20, 2012.

[23] R.A. Rana, S.A. Patel, A. Muthusamy, C.W. Lee, H.J. Kim, "Review of Multilevel Voltage Source Inverter Topologies and Analysis of Harmonics Distortions in FC-MLI," Electronics, vol. 8, no. 11, pp. 1-37, 2019.

[24] S. Mirjalili, Moth-Flame Optimization Algorithm: A Novel Nature-Inspired Heuristic Paradigm," KnowledgeBased Systems, vol. 89, pp.228-249, 2015.

[25] F. Chabni, R. Taleb, A. Lakhedar, M. Bounadja, "New Modified CHB Multilevel Inverter Topology with Elimination of Lower and Higher Order Harmonics", Automatika, vol.59, no. 1, pp.1-10, 2018. 